\title{
The Physical Simulation Experiment on the Effect of Mining Height and Critical Layer on Overburden Rock Fracture
}

\author{
Li Shugang $^{1}$, Li Zhiliang ${ }^{1}$, Li Haifei ${ }^{1}$ \\ ${ }^{1}$ Xi'an University of Science and Technology, Xi'an 710054 China
}

Key words: fracture, mining height, first sub-key strata, caving zone, fissure zone

Abstract: By employing the physical simulation experiment and theoretical analysis, this paper aims to study the effect of mining height and the first sub critical layer on the evolution law of mining-induced fractures. The mining-induced fracture density, fissure characteristics, height of broken fractures, height of separated strata and their correlation with mining height and the first sub critical layer are analyzed quantitatively. As mining fissure is the key area to gas extraction, the authors fully consider the mining height and the location of the first sub critical layer, so as to determine their relatioinship. Through extracting pressure relief gas in test mine, we have verified the effect of mining height and the first sub key layer on broken fracture height, providing a theoretical basis for parameter arrangement of extracting pressure relief gas.

\section{Introduction}

With the increasing depth and intensity of mining, the number of gas-related accidents is also growing, which seriously restricts the safety and efficiency of mining. Meanwhile, mine gas occurrence in China has the feature of "three highs and three lows", which affects gas pre-pumping. In order to improve gas drainage effect, high pumping lane and high-level borehole have become effective means to control gas. In terms of relief-pressure gas drainage, gas gathers in caving zone and fracture in overlying strata after mining where high pumping lane and high-level borehole are layout to extract high concentration gas, thereby reducing gas emission in working face and achieving the purpose of gas control. Over the years, domestic and foreign scholars have made many tests and theoretical analysis ${ }^{[1-5]}$ on underground mining fissure development, morphological characteristics [6-12] and coal rock fracture distribution, and have made great achievements that guide the safety and effencicy of coal mining. As complex evolution of underground mining crack and characteristic are affected by mining height and the first sub critical layer, we have studied the relationship among mining fracture morphology, mining height and the first sub critical layer, and then we have determined proper gas drainage methods and parameters. All these efforts provide a theoretical foundation and practical application 
value of exploring suitable gas drainage technology and controlling gas disaster in coal minning.

\section{Similar physical model building}

\section{Experimental model}

The main mininig coal seam of the test mine is Taiyuan group 15\# coal seam. This layer is positioned at the lower part of Taiyuan formation, above K1 sandstone limestone, under $\mathrm{K}_{2}$ limestone, $130 \sim 150 \mathrm{~m}$ away from $3 \#$ the coal seam, $12 \sim 24 \mathrm{~m}$ away from $\mathrm{K}_{2}$ limestone, and about $20 \mathrm{~m}$ away from the $\mathrm{K} 1$ sandstone. The coal is characterized by its large thickness and deposition stability. According to drilling data, the coal seam thickness is from 0 to $5.71 \mathrm{~m}$, with an average of $5.1 \mathrm{~m}$, and the angle is from 1 degree to 15 degrees, with an average of 8 degrees. By employing long-wall mechanized mining full height mining method, the mining height is $3.87 \sim 5.1 \mathrm{~m}$. Immediate roof is mudstone, dark gray to black, containing sand partly; old roof is sandstone, gray to grayish black and sorting are round in shape and with calcitic cementation; direct bottom is aluminum mudstone, grayish black. For physical and mechanical properties of coal and rock strata, see Table 1.

Table 1 Physical and mechanical properties of model

\begin{tabular}{|c|c|c|c|c|c|c|c|c|}
\hline $\begin{array}{l}\text { Serial } \\
\text { number }\end{array}$ & Name & $\begin{array}{l}\text { Volume- } \\
\text { weight } \\
/ \mathrm{kN} \cdot \mathrm{m}^{-3}\end{array}$ & $\begin{array}{l}\text { Elasticity } \\
\text { modulus } \\
\text { /Mpa }\end{array}$ & $\begin{array}{c}\text { Compressive } \\
\text { strength } \\
/ \mathrm{Mpa}\end{array}$ & $\begin{array}{c}\text { Poisson } \\
\text { ratio }\end{array}$ & $\begin{array}{c}\text { Cohesion } \\
\text { /Mpa }\end{array}$ & $\begin{array}{c}\text { Dilatancy } \\
\text { angle } \\
/\left(^{\circ}\right)\end{array}$ & $\begin{array}{l}\text { Nternal } \\
\text { friction } \\
\left.\text { angle/ ( }{ }^{o}\right)\end{array}$ \\
\hline 1 & Mudstone & 20.80 & 20019 & 20.5 & 0.195 & 0.93 & 8 & 31 \\
\hline 2 & Sandy mudstone & 26.40 & 56767 & 48.8 & 0.278 & 1.38 & 8 & 34 \\
\hline 3 & Medium sandstone & 26.60 & 50430 & 65.1 & 0.28 & 2.27 & 10 & 31 \\
\hline 4 & Carbon mudstone & 15.00 & 35234 & 14.8 & 0.24 & 0.78 & 8 & 22 \\
\hline 5 & Packsand & 26.20 & 43020 & 69 & 0.26 & 1.93 & 10 & 31 \\
\hline 6 & Ssiltstone & 26.00 & 54739 & 58.5 & 0.253 & 1.3 & 12 & 35 \\
\hline 7 & Limestone & 26.50 & 46636 & 91.2 & 0.23 & 3.1 & 12 & 41 \\
\hline 8 & $\begin{array}{l}\text { Aluminum } \\
\text { mudstone }\end{array}$ & 13.00 & 40500 & 16 & 0.25 & 0.83 & 8 & 24 \\
\hline 9 & coal & 14.60 & 14142 & 13.5 & 0.275 & 0.72 & 8 & 20 \\
\hline
\end{tabular}

\section{Experimental model design}

The mining coal seam overburden distribution is the experimental model, and its mining height is 5 meters, and the first sub critical layer is 20 meters. We adjust the 
mining height to $1 \mathrm{~m}, 3 \mathrm{~m}$ and $5 \mathrm{~m}$ and the first sub critical layer to $10 \mathrm{~m}, 20 \mathrm{~m}$ and $30 \mathrm{~m}$ as the experimental object. We study fracture development process of overlying rock in different mining heights and the first sub critical layer. In the similar physical simulation experiment, by obersving floor stress, abscission rate after caving, fracture density, caving range, caving type, broken feature in the process of mining, we study the deformation rule of overburden movement and fracture distribution, and the influence rule of mining height and the first sub key strata on development and the evolution of mining fracture.

\section{Experimental process}

The distance between open-off cut and model boundary is $10 \mathrm{~cm}$. The similarity ratio is $1: 100$, and open-off cut is $8 \mathrm{~cm}$, so the original is $8 \mathrm{~m}$; Every advancing distance is $2 \mathrm{~m}$, and every $20 \mathrm{~min}$ per advancing.

\section{The mining fracture evolution characteristics under different mining heights}

\section{Mining fissure expansion characteristics under different mining heights}

Fissure development under different mining heights is shown in Figure 1. We can conclude that delamination fracture with 1,3 and $5 \mathrm{~m}$ mining height develop noticeably, $12.5,32.5$ and $43.5 \mathrm{~m}$ away from coal seam roof, and mainly in bending deformation.

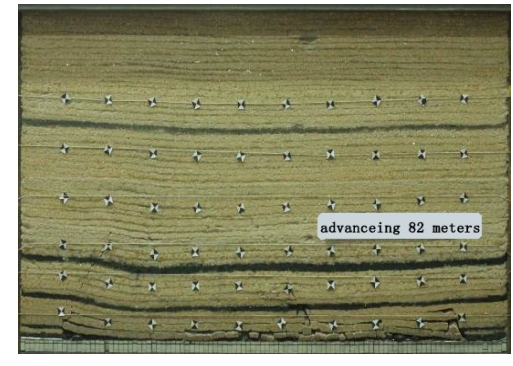

(1) Mining hight is $1 \mathrm{~m}$

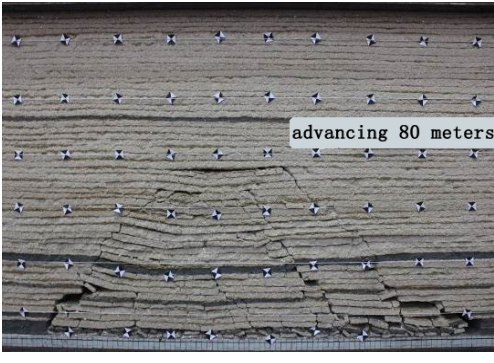

(2) Mmining hight is $3 \mathrm{~m}$

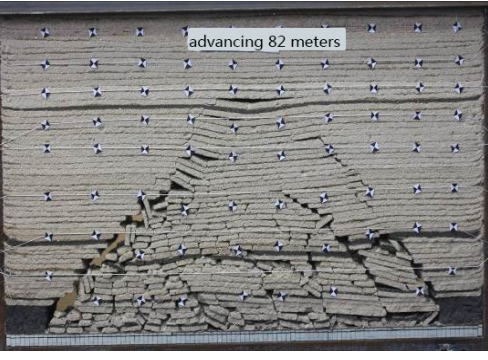

(3) Mining hight is $5 \mathrm{~m}$

Figure 1 Types of mining fracture development under different mining heights

Broken characteristics of rock mass are measured by broken expansion coefficient; differential and integral thought is used to deal with cracks produced during experiment. The broken bulking coefficient is obtained under different mining heights, as shown in Figure 3.

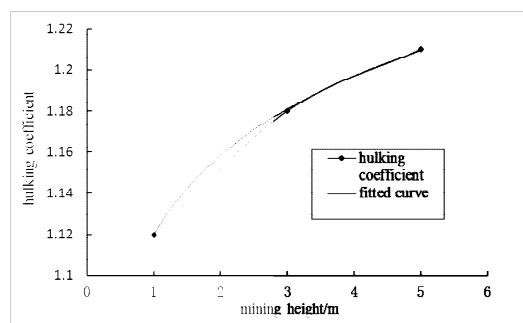

Figure2 Curve of bulking coefficient affected by mining height 
Curve of bulking coefficient affected by mining height is fitted, and the relationship between bulking coefficient and mining height is:

$$
\mathrm{K}_{\mathrm{p}}=0.0557 \mathrm{ln} \mathrm{M}+1.1197
$$

In the formula, $K_{p}$ is bulking coefficient; $M$ is mining height, $\mathrm{m}$.

As shown in Figure 2, with the increasing of mining height, bulking coefficient of the same mining overburden layers increases. It is positively correlated between bulking coefficient and the logarithm of mining height. The mining height will not affect the bulking coefficient when mining height reaches a certain value

\section{Analysis of mining-induced fracture under the different mining heights}

Broken fissure, bed separated fissures and strata movement of the mining overlying stratum are not fully synchronized, and development of mining overlying strtum is not in uniform motion. The relation between caving zone height, fissure zone height and mining height is shown in Figure 3. With the increasing of mining height, fissure zone height increases. It is positively correlated between fissure height and the logarithm of mining height. The growth speed will decrease when mining height reaches a certain value. With the increasing of mining height, caving zone height increases, and it is a linear positive correlation between caving zone height and mining height.

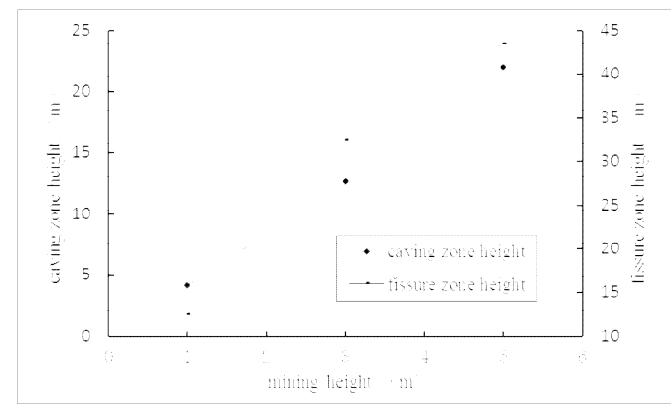

Figure 3 Relation between mining fissure height with mining heght

By analyzing the caving zone height and fissure zone height under different mining heights, we can obtain the following formula $(2) \sim(3)$. In the formula, $G$ is caving zone height, $\mathrm{m} ; F$ is fissure zone height, $\mathrm{m} ; M$ is mining height, $\mathrm{m}$.

$$
\begin{gathered}
G=4.475 \mathrm{M}-0.525 \\
F=19.093 \mathrm{ln} M+12.265
\end{gathered}
$$

\section{The effect of first sub key strata on evolution and distribution characteristics}

\section{The mining fissure broken characteristics under different first sub key strata}

The first sub-key stratum in test coal mine is $\mathrm{K}_{2}$ limestone. As the distribution is uneven, the position of the first sub-key strata in the experimental model is adjusted to $10 \mathrm{~m}, 20 \mathrm{~m}, 30 \mathrm{~m}$. When working face advances to a certain value, mining fissure 
development form is shown in Figure 4.

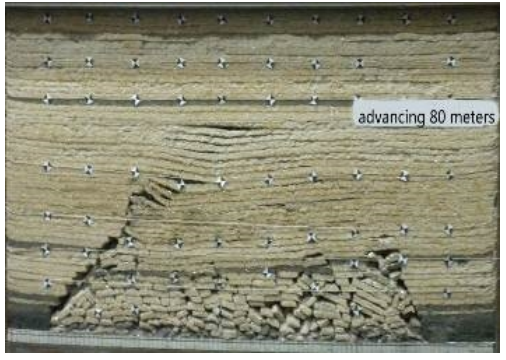

(1) $\mathrm{K}_{2}$ limestone is $10 \mathrm{~m}$

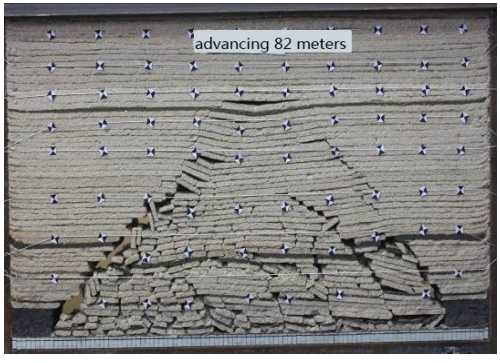

(2) $\mathrm{K}_{2}$ limestone is $20 \mathrm{~m}$

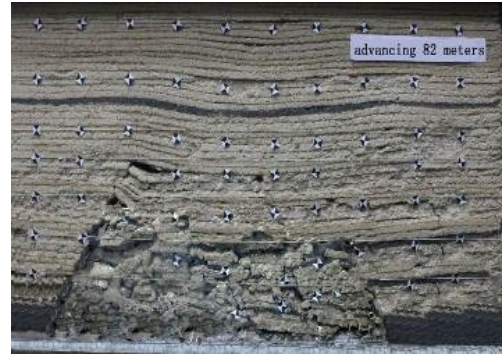

(3) $\mathrm{K}_{2}$ limestone is $30 \mathrm{~m}$

Figure 4 Mining fracture evolution curves under different first sub key strata

By fitting the whole bulking coefficient $K_{p}$, the bulking coefficient in caving zone $\mathrm{Kpg}$, the bulking coefficient in fracture zone Kpf and the first sub key layer horizon, we can obtain the relationship between bulking coefficient of different zone and the first sub key layer horizon, as shown in formula 5.

$$
\begin{gathered}
\mathrm{K}_{\mathrm{P}}=-0.027 \mathrm{lnL}+1.193 \\
\mathrm{~K}_{\mathrm{Pg}}=-0.027 \mathrm{lnL}+1.232 \\
\mathrm{~K}_{\mathrm{Pf}}=-0.027 \mathrm{lnL}+1.153
\end{gathered}
$$

In the formula, $K_{p}$ is the whole bulking coefficient; $K_{p g}$ is the bulking coefficient in caving zone; $K_{p f}$ is the bulking coefficient in fracture zone; $L$ is the first sub key layer horizon, $\mathrm{m}$.

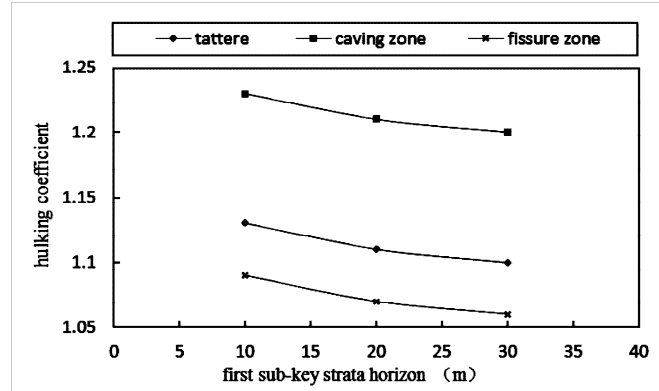

Figure 5 Relationship between bulking coefficient and first sub-key strata

We can see from Figure 5, with the working face advancing, mining dynamic overburden bulking coefficient between each measuring line and the roof of coal seam decrease with the increase of the first sub key strata. From Figure 5 and formula (4), (5), (6), the whole bulking coefficient, the bulking coefficient in caving zone, and the bulking coefficient in fracture zone increase with the first sub strata decreasing, and the coefficient and log of the first sub key layer horizon has a negative correlation.

\section{Mining-induced fracture height under different first sub key layer horizon}

In order to study how the first key sub layer affect the evolution of mining fissure, how the mining overburden fracture height and falling height change with the first sub critical layer needs further research. Figure 8 shows the distribution of fractured zone 
and caving zone when the first sub key layer horizon is $10 \mathrm{~m}, 20 \mathrm{~m}$ and $30 \mathrm{~m}$.

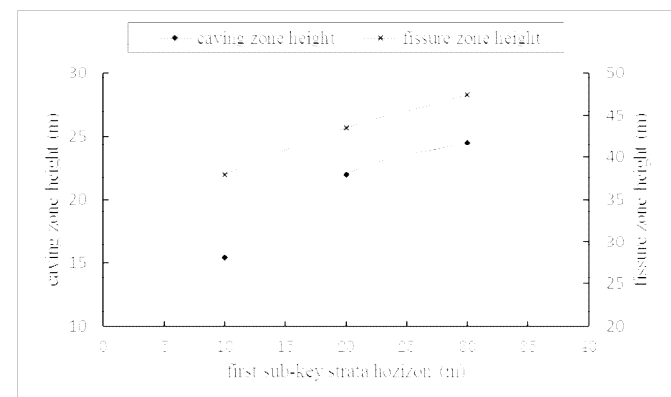

Figure 6 Caving zone and fissure zone in different first sub-key strata

By fitting the height of the caving zone $G$, the height of crack belt $F$ and the first sub key layer horizon under different horizon of K2, we can obtain formula (7) - (8).

$$
\begin{gathered}
F=8.48931 \mathrm{~nL}+18.349 \\
G=8.4166 \mathrm{ln} \mathrm{L}-3.7733
\end{gathered}
$$

In the formula, $F$ is the height of crack belt, $\mathrm{m} ; \mathrm{G}$ is the height of the caving zone; $\mathrm{L}$ is the first sub key layer horizon, $\mathrm{m}$.

Figure 8 and Formula (7), (8) shows that with the increase of the first sub key strata, the height of caving zone and crack belt grows accordingly. The log of the first sub key layer horizon shows a positive correlation.

\section{Effect of mining height and first sub key layer horizon on mining fracture}

Regarding to the mining area concerning gas extraction, to carry out research on mining fissure development, especially on the height of the caving zone and the height of crack belt within the scope of mining fracture plays an important role in instructing the mining work of gas drainage in pressure releasing area.

To determine the height of caving zone and fractured zone under the geological conditions of the test mining area and to guid following production, field investigation and similar physical simulation experiment are combined to study the mining height and the first sub key layer horizon effect on mining fracture evolution.

\section{Analysis of fractured zone height}

During the period of working surface stoping, overlying strata emgeres periodic caving with the working face advancing, thus forming the caving zone and fractured zone. In the process, relationship between caving zone, fractured zone and mining height is shown as:

$$
\mathrm{M}+\mathrm{F}=[\mathrm{F}+(1-\mathrm{c}) \cdot \mathrm{M}] \cdot \mathrm{K}_{\mathrm{p}}
$$

In the formula, $M$ is mining height, $\mathrm{m} ; F$ is height of crack belt, $\mathrm{m} ; c$ is stoping rate; $K_{p}$ is the whole bulking coefficient.

Meanwhile, according to 3.2 , the relationship between the bulking coefficient of mining fissure and the first sub key strata can be obtained: 


$$
\mathrm{K}_{\mathrm{p}}=\mathrm{p} \ln \mathrm{L}+\mathrm{q}_{1}
$$

In the formula, $\mathrm{L}$ is the first sub key layer horizon, $\mathrm{m} ; \mathrm{p}$ and $\mathrm{q} 1$ are coefficients, and their value are mainly determined by the overlying strata lithology, $p$ is negative and $\mathrm{q}_{1}$ is positive.

Substituting formula (10) into (9), we can obtain the relationship between height of crack belt, mining height and the first sub key strata:

$$
F=M \cdot\left(\frac{c}{1-\frac{1}{p \ln L+q_{1}}}-1\right)
$$

For mechanized mining face of the test mining area, the recovery rate is more than $90 \%$, and the $\mathrm{C}$ value is 1 ; $\mathrm{P}$ is -0.027 ; $\mathrm{Q}$ is 11.183 . Relationship of height of crack belt, mining height and the first sub key layer horizon in test mining area is

$$
F=\frac{M}{0.153-0.027 \operatorname{ln~L}}
$$

\section{Analysis of the caving zone height}

In the process of mining face, caving zone formation precedes the fractured zone. Many scholars have made a lot of research on determining the height of caving zone and obtained the empirical relationship between the caving zone and the mining height. However, the first sub key strata has certain influence on the caving zone height, and relationship between the caving zone height, the height of fracture zone and the mining height after the formation of the mining fissure zone is shown as:

$$
\mathrm{M}=\mathrm{G} \cdot\left(\mathrm{K}_{\mathrm{pg}}-1\right)+(\mathrm{F}-\mathrm{G}) \cdot\left(\mathrm{K}_{\mathrm{pf}}-1\right)+\mathrm{M} \cdot(1-\mathrm{C}) \cdot \mathrm{K}_{\mathrm{p}}
$$

In the formula, $G$ is the height of the caving zone, $\mathrm{m}$; $M$ is mining height, $\mathrm{m} ; F$ is the height of crack belt, $\mathrm{m}$; $K_{p g}$ is the bulking coefficient in caving zone; $K_{p f}$ is the bulking coefficient in fracture zone; $c$ is stoping rate; $K_{p}$ is the whole bulking coefficient.

Meanwhile, according to the 3.2, relationship between bulking coefficient in caving zone, the bulking coefficient in fracture zone and the first sub key layer horizon can be obtained:

$$
\begin{aligned}
& \mathrm{K}_{\mathrm{p}}=\mathrm{p} \ln \mathrm{L}+\mathrm{q}_{2} \\
& \mathrm{~K}_{\mathrm{p}}=\mathrm{p} \ln \mathrm{L}+\mathrm{q}_{3}
\end{aligned}
$$

In the formula, $\mathrm{L}$ is the first sub key layer horizon, $\mathrm{m}$; p, q2 and q3 are coefficients, and their value are mainly determined by the overlying strata lithology; $p$ is negative, while $\mathrm{q} 2$ and $\mathrm{q} 3$ are positive.

Substituting formula (10), (11), (14), (15) into (13) can obtain the relationship between the height of fracture zone, the mining height and the first sub key layer 
horizon:

$$
G=M \cdot \frac{\left(q_{1}-q_{3}\right) \cdot\left[1-(1-c) \cdot\left(p \ln L+q_{1}\right)\right]}{\left(q_{2}-q_{3}\right) \cdot\left(p \ln L+q_{1}-1\right)}
$$

For mechanized mining face in test mining area, recovery rate is more than $90 \%$; $\mathrm{C}$ value is $1 ; \mathrm{P}$ is $-0.027 ; \mathrm{q}_{1}, \mathrm{q}_{2}$, and $\mathrm{q}_{3}$ are $1.183,1.212,1.163$ respectively. Then the relationship between height of crack belt, mining height and the first sub key layer horizon in test mining area is

$$
G=\frac{0.408 \mathrm{M}}{0.183-0.027 \ln \mathrm{L}}
$$

\section{Engineering application}

\section{Engineering background}

Test face mainly mines the Taiyuan group 15\# coal seam, and its thickness is $4.85 \sim 5.71 \mathrm{~m}$, averaging $5.1 \mathrm{~m}$. Dip angle is $1^{\circ} \sim 15^{\circ}$, with an average of $8^{\circ}$. By adopting the method of longwall mechanized mining full height mining, the mining height reaches $5.1 \mathrm{~m}$.

\section{High level suction roadway pressure relief drainage gas technology}

Test face is the first mining face, and the main source of gas is coal seam, gob and adjacent layer. Because 15\# coal seam permeability is not high, and pre-pumping effect is not as expected, reservoir migration area of gas in mining fissure is the key to effective gas drainage. According to coal seam occurrence and overlying strata distribution, we can obtain that fracture zone height is $45.5 \mathrm{~m}$ and caving zone height is $22.8 \mathrm{~m}$ from formula (14) and (19). Thus the high drainage roadway of test face lies $27.8 \mathrm{~m}$ away from coal seam roof, so as to ensure the high extraction efficiency in high drainage roadway.

\section{Analysis of the effect of extraction}

Through studying the results of high level suction roadway drainaging gas in the test working face (as shown in Figure 7), we obtain the following data: during normal working hours, the averag pure quantity of extraction reaches $52.9 \mathrm{~m}^{3} / \mathrm{min}$, and drainage volume accounts for $69.5 \%$ of total methane emission. In May 2013 to July 2014, the working face advances $1542 \mathrm{~m}$, and coal output is 2 milliont. Working face, upper corner and return air lane maximum gas volume fraction are controlled within $1 \%$, which has realized efficien and safe production in working face. 


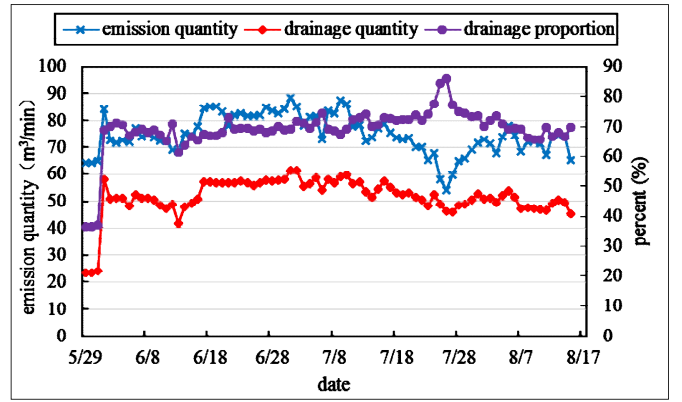

Figure 7 Drainage volume in high drainage roadway

\section{Conclusion}

(1) By physical simulation experiment, effect of mining height and the first sub critical layer on crack density, broken characteristics, broken fissures and delamination crack height in evolution process of mining fracture is analyzed quantitatively.

( 2 ) Coal layer and rock layer are distributed unevenly in test mining area. Combining influence of mining height and the first sub key strata on mining fissure evolution, formula are obtained to calculate the height of caving zone and fracture zone, when comprehensively consider the effects of mining height and the first sub critical layer.

( 3 ) Throught analysis of the actual fracture height and effect of drainage pressure relief gas, the formula can be applied to calculate the height of fractured in this mine, and to provide a theoretical basis for drainage parameters of pressure relief gas.

\section{Reference}

[1] Li Shugang, Shi Pingwu, Qin Minggao. The research of elliptic paraboloid zone's dynamic distribution characteristics on overlying fissure [J]. Mining pressure and strata control, 1999, (3-4):44- 46.

[2] Lin Haifei, Li Shugang, Cheng Lianhua, etc. Experimental analysis of dynamic evolution model of mining-induced fissure zone in overlying strata $[\mathrm{J}]$. Journal of mining and safety engineering, 2011, 28(2):298-303.

[3] Qian Minggao, Xu Jialin. Study on the "O-shape" circle distribution characteristics of mining-induced fractures in the overlaying strata $[\mathrm{J}]$. Journal of china coal society, 1998, 23(5):466- 469.

[4] Li Shugang, Lin Haifei. Model experiment analysis of distribution features of mining fissure elliptic paraboloid zone [J], coal, 2008, 16(2):19-21.

[5] Xu Jialin, Qian Minggao, Jin Hongwei. Study and application of bed separation distribution and development in the process of strata movement [J], Chinese 
journal of geotechnical engineering, 2004, 25(5):632-636.

[6] Qian Minggao, Shi Pingwu, Xu Jialin, Mining pressure and strata control [M]. Xuzhou: China University of Mining and Technology press. 2010.

[7] Li Shugang, Qian Minggao, Xu Jialin. Simultaneous ex2tracti on of coal and coalbedmethane in China [J]. Mining Science and Technology, 1999, 99 (10): 357 360

[8] Cheng yuanping, Yu Qixiang, Yuan liang. Gas extraction techniques and movement properties of long distance and pressure relief rock mass upon exploited coal seam $[J]$. Journal of Liaoning Technical University (Natural Science Edition), 2003, 22(4):483 486.

[9] Xu Jialin, Qian Minggao. Study and application of mining-induced fracture distribution in green mining $[\mathrm{J}]$. Journal of China University of Mining \&Technology, 2004, 33(2):141-144.

[10] Sun Haitao, Hu Qianting, Zheng Yingren, etc, Determination method of separated layer displacement in overburden strata above coal mining face and application [J]. Coal science and technology, 2011,39(1):16-19.

[11] Cheng Yuanping, Yu Qixiang. Development of regional gas control technology for Chinese coalmines [J]. Journal of Mining \& Safety Engineering, 2007, 24 (4):383 386.

[12] Lin Haifei, Li Shugang, Cheng Lianhua. Gas emission characteristics and management of coal caving based on change of underground pressure $[\mathrm{J}]$. Journal of Xi' an university of science and technology, 2004,24 (1) :15-18. 